\title{
Habilidades sociales para construir relaciones de paz: Proyecto de vinculación con el Centro de Estudios Científicos y Tecnológicos del Estado de Sonora
}

\author{
(CECyTE Sonora, Plantel Hermosillo II)
}

\section{Dolores Guadalupe Morales Flores*}

Las habilidades sociales son parte importante de toda actividad humana, no solo por su dimensión relacional, sino por su influencia en las áreas familiar, escolar y social, ya que estas influirán en la forma de interactuar con su entorno más próximo.

Cuando existe una carencia de habilidades sociales, se favorece la aparición de actitudes y conductas disfuncionales que impactan negativamente, tanto a nivel individual, como social. Es por ello que reviste una vital importancia la formación de los jóvenes en estas destrezas sociales que les permitan formarse como seres humanos equilibrados, con relaciones interpersonales saludables.

Es así, que la práctica de habilidades sociales, sienta las bases para crear ambientes armónicos y pacificadores donde se desarrollen y fortalezcan los sistemas de valores, se creen nuevas y mejores formas de relacionarse y se provea a las y los jóvenes de factores protectores para su óptimo desarrollo y que a la vez se conviertan en agentes

\footnotetext{
* Maestra de tiempo completo de la Licenciatura en Trabajo Social, Universidad de Sonora. Correo: lolymoralesf@sociales.uson.mx
} 
multiplicadores de paz, tanto en sus familias como en sus comunidades.

Por ello se hace cada vez más necesario crear ambientes y espacios participativos

Donde se privilegie la paz como alternativa para construir mejores relaciones interpersonales e impactar así la vida social, desarraigando cada vez más la cultura de la violencia.

Y como una respuesta concreta a esta necesidad, se implementó el curso taller Habilidades sociales para construir relaciones de paz, dentro del marco de vinculación del Departamento de Trabajo Social de la Universidad de Sonora, con el Centro de Estudios Científicos y Tecnológicos del Estado de Sonora (CECyTE Sonora, Plantel Hermosillo II), a fin de contribuir al fortalecimiento de habilidades sociales en los jóvenes que asistan a este plantel educativo, coadyuvando así a una formación más integral donde se vivan procesos de democracia y construcción de paz.

En este curso taller se trabajó en el periodo de marzo a mayo de 2017, con jóvenes de dieciséis a dieciocho años, a los cuales se les brindaron herramientas que les permitieron fomentar las relaciones sociales y promover la creación de entornos pacíficos, creando así factores protectores para su óptimo desarrollo, tanto en su ámbito familiar, como en los grupos sociales en donde se desenvuelven.

\section{Objetivo general}

Proporcionar a los estudiantes herramientas que les permitan potencializar sus relaciones interpersonales para la construcción de la paz.

\section{Objetivos específicos}

- Fortalecer las habilidades de asertividad, empatía y escucha activa, a fin de mejorar las relaciones interpersonales.

- Propiciar el uso de herramientas sociales para favorecer el trabajo en equipo.

- Promover interacciones positivas que contribuyan a un óptimo desarrollo individual y social.

- Sensibilizar sobre los beneficios de utilizar prácticas pacificadoras en sus relaciones sociales.

La metodología utilizada durante las sesiones de trabajo estuvo basada en el modelo constructivista. Se buscó en todo momento que el participante practicara y reforzara habilidades sociales tales como la asertividad, empatía y escucha activa, así como el uso de herramientas sociales que favorecen el trabajo en equipo.

Así mismo, se sensibilizó a los participantes sobre los beneficios de utilizar prácticas pacificadoras en sus relaciones sociales, a través de técnicas vivenciales que propiciaran la sana convivencia e impactaran en su calidad de vida.

Para generar un dinamismo en el grupo, se trabajó con técnicas expositivas, ejercicios lúdicos y reflexivos, así como con la proyección de audios y videos.

Las actividades se realizaron en diez sesiones de dos horas cada una, dos veces por semana, haciendo un total de veinte horas.

Durante el desarrollo del cuso taller se tuvo muy buena asistencia y participación activa por parte de los jóvenes. Los temas abordados fueron de su interés $y$ estuvieron reforzados con técnicas 
grupales que les resultaron dinámicas y atractivas; además, propiciaron la reflexión e interacción entre ellos.

Las relaciones interpersonales se tornaron cada vez más cercanas y respetuosas, a medida que avanzaban las sesiones. Eso se reflejó en el ambiente que prevalecía en el grupo, ya que se les brindaron herramientas para que desarrollaran habilidades sociales, mismas que los participantes asimilaron y aplicaron en los diferentes ejercicios didácticos que se implementaron a lo largo del curso taller.

Los temas que se abordaron sentaron las bases para establecer relaciones pacíficas y colaborativas, primeramente entre los asistentes, para después impactar sus entornos familiares $y$ escolares. Con ello, se incorporaron en su formación esquemas que van a privilegiar acciones a favor de la paz.

\section{Metas alcanzadas}

- Durante el desarrollo del curso taller, se logró que el $75 \%$ de los participantes se involucraran en las actividades. Esto se reflejó en la asistencia y participación activa durante las diferentes acciones implementadas en cada sesión.

- En cuanto al tema del trabajo en equipo, se logró que el $75 \%$ conociera su importancia y ventajas, a partir de los ejercicios y tareas desarrolladas con sus compañeros.
- Se logró que el $80 \%$ de los asistentes al curso taller identificaran habilidades de interacción saludables, ya que mejoraron el trato y la comunicación, siendo más asertivos y respetuosos a la hora de relacionarse con sus pares.

- $\quad$ El $95 \%$ de los asistentes conocieron los beneficios de las prácticas pacificadoras y cómo estas impactan positivamente en sus relaciones sociales. También se pudo apreciar, a través de análisis de casos realizados por equipos y la representación de situaciones, que reforzaron el tema impartido.

\section{Bibliografía}

Aguilar, G., Peter, M. y Aragón, L. (2014). Desarrollo de habilidades sociales en niños y adolescentes: programa para padres, docentes y psicólogos. México: Trillas.

Ander Egg, E. y Aguilar Idáñez, M.J.(2001). El trabajo en equipo. México: Progreso.

Ferreiro, R. (2008). La creatividad: Un bien cultural de la humanidad. México: Trillas.

Goleman, D. (2006). La inteligencia emocional. México: Vergara.

Romero Ibarrola, N. (coord.) (2004). Guía de Padres vol. 3: 13 a 15 años. México: Infantil y Educación. 


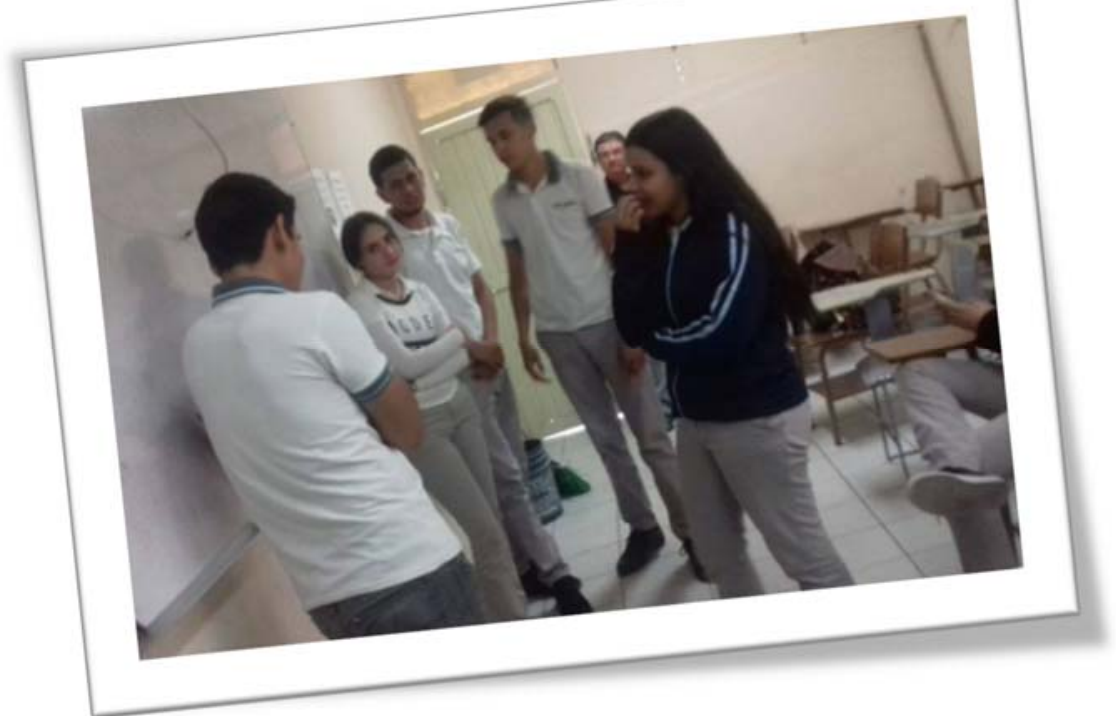

Foto 1: Dolores Guadalupe Morales Flores (2017). Técnica Grupal. 


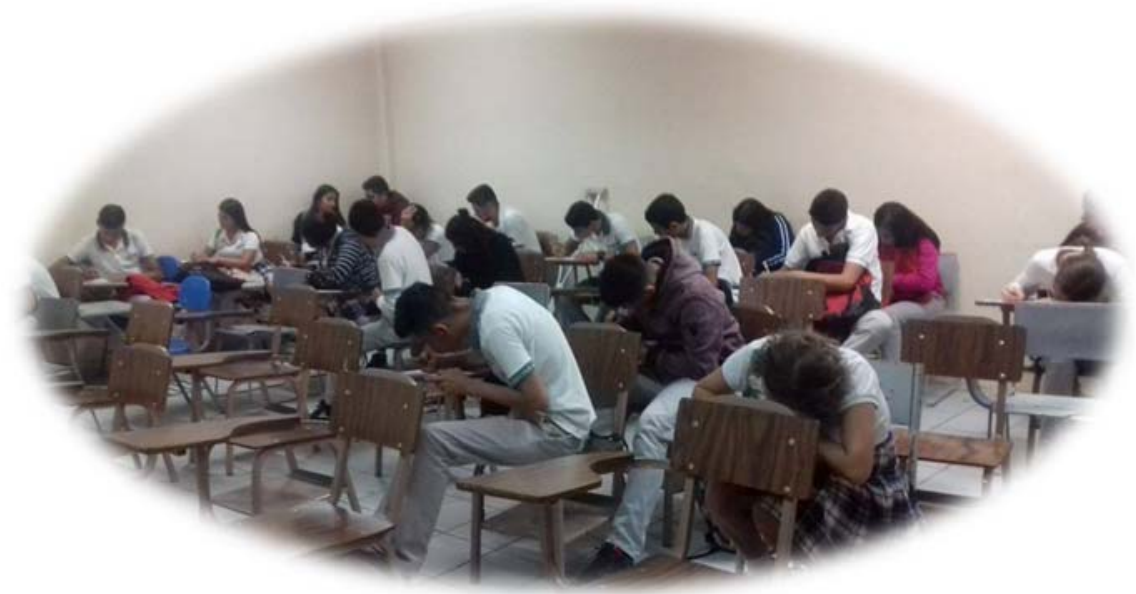

Foto 2: Dolores Guadalupe Morales Flores (2017). Sesión. 


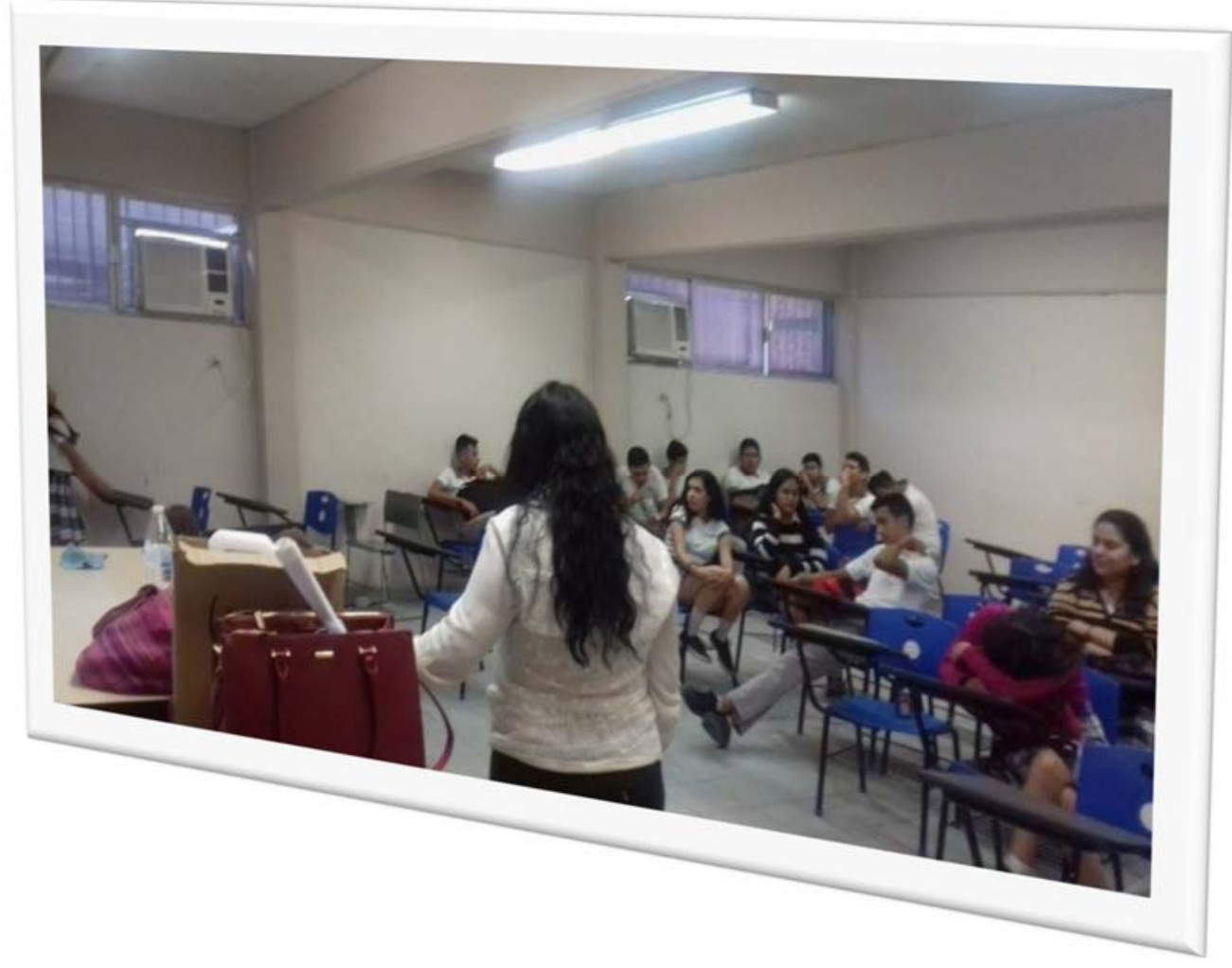

Foto 3: Dolores Guadalupe Morales Flores (2017). Exposición. 